\title{
ANÁLISE DA UTILIZAÇÃO DO COAGULANTE TANINO NA REMOÇÃO DA COR, TURBIDEZ A DQO DO EFLUENTE TEXTIL DE UMA LAVANDERIA INDUSTRIAL.
}

\author{
A P. C. SOUZA ${ }^{1}$; E.A. M. SOUZA ${ }^{1}$;N. C. PEREIRA ${ }^{2}$ \\ ${ }^{1}$ Universidade Tecnológica Federal do Paraná, Departamento de Engenharia Civil \\ ${ }^{2}$ Universidade Estadual de Maringá, Departamento de Engenharia Química \\ E-mail para contato: paulacsouza@uol.com.br
}

\begin{abstract}
RESUMO - O objetivo da pesquisa foi avaliar a eficiência de remoção do coagulantes tanino nos processos de tratamento efluente têxtil de uma lavanderia industrial, considerando a remoção de cor, turbidez e DQO comparando os resultados com o coagulante sulfato de alumínio. Os ensaios foram realizados em equipamento de bancada Jar-test. O tempo de mistura rápida foi de 5 minutos, mistura lenta de 30 minutos e de sedimentação de 30 minutos, as velocidades de misturas mantiveram-se em 95 rpm (TMR) e $35 \mathrm{rpm}$ (TML). Utilizou as dosagens de tanino de 80;90;100;110;120;130 $\mathrm{mg} / \mathrm{L}$, sendo considerada a concentração de $80 \mathrm{mg} / \mathrm{L}$ com o melhor desempenho do coagulante tanino para o efluente tratado, e para esta concentração verificou remoções de $87 \%$ de cor, $90 \%$ da turbidez e $15 \%$ da matéria orgânica do efluente. Para o sulfato de alumínio, a melhor concentração ocorreu na dosagem de $300 \mathrm{mg} / \mathrm{L}$, com remoções de $56 \%$ de cor, $95 \%$ da turbidez e $39 \%$ da matéria orgânica do efluente real.
\end{abstract}

\section{INTRODUÇÃO}

A indústria têxtil utiliza grandes volumes de água em seu processamento, sendo esta uma dos principais insumos. O efluente gerado traz consigo uma alta carga poluidora, uma vez que cerca de 90\% dos produtos químicos utilizados no beneficiamento têxtil são eliminados após cumprirem seus objetivos. Este tipo de indústria gera efluentes com composição extremamente heterogênea e uma grande quantidade de material tóxico e recalcitrante, o que torna seu tratamento complexo.

O efluente têxtil, além de apresentar uma forte coloração, possuem grande quantidade de sólidos suspensos, $\mathrm{pH}$ altamente flutuante, temperatura elevada, além de elevadas concentrações de DQO, considerável quantidade de metais pesados $(\mathrm{Cr}, \mathrm{Ni}$ ou $\mathrm{Cu})$, compostos orgânicos clorados e surfactantes (Araujo e Yokoyama, 2006).

O estudo de novas alternativas capazes de minimizar o volume empregado de água nos processos industriais e/ou propiciarem seu reuso, bem como, reduzir sua toxicidade é uma das principais armas de combate à contaminação ambiental (Sauer, 2002). Algumas combinações de técnicas físico-químicas foram testadas, coagulação química, seguido por sedimentação e absorção, processos de ozonização e de oxidação. Devido ao elevado capital e custos destes métodos de 


\section{9 a 22 de outubro de 2014 \\ Florianópolis/SC}

funcionamento, existe uma necessidade de pesquisar métodos mais eficiente e barato com consumos mínimos de químicos e de energia.

Neste contexto o objetivo da pesquisa foi avaliar a eficiência de remoção do coagulante tanino nos processos de tratamento de água de uma lavanderia industrial, considerando os parâmetros de remoção de cor, turbidez e DQO e comparar os resultados com o do coagulante sulfato de alumínio utilizado pela lavanderia.

\subsection{MATERIAIS E MÉTODOS}

As amostras provêm de uma lavanderia industrial localizada no município de Campo Mourão, noroeste do estado do Paraná. O efluente estudado tem origem de processos de lavagem e beneficiamento de Jeans de uma lavanderia têxtil, e serão caracterizadas em relação a sua coloração específica (PtCo APHA e Absorbância), pH, turbidez, sólidos, demanda química de oxigênio (DQO) e demanda biológica de oxigênio (DBO).

Os experimentos de coagulação/floculação foram realizados em equipamento jar-test simples, Milan - Modelo JT 101/6, com regulador de rotação das hastes misturadoras, em temperatura ambiente. A metodologia empregada no experimento foi a adotada por Couto Jr (2011), na qual adiciona-se diferentes dosagens de coagulantes em uma amostra $(500 \mathrm{~mL})$ de efluente em béqueres de prova. Inicialmente foram adotados os tempos de misturas e sedimentação utilizadas por Couto $\mathrm{Jr}$ (2011), ou seja, 5 minutos para o tempo de mistura rápida (TMR), 30 minutos para o tempo de mistura lenta (TML) e sedimentação (SED) de 30 minutos. Após o ensaio de coagulação/floculação as amostras foram mantidas em repouso por um período de 20 ou 30 minutos, para que ocorressem a sedimentação do material e então analisadas. Na sequencia coletou-se o sobrenadante da amostra de cada béquer, para análise dos parâmetros, a fim de verificar a eficiência de remoção pela comparação dos resultados com o efluente bruto.

A determinação dos parâmetros: DQO, cor, turbidez, sólidos totais (ST) e sólidos suspensos (SS), sólidos dissolvidos (SD), sólidos suspensos totais (SST), sólidos suspensos fixos (SSF) e sólidos suspensos voláteis (SSV), foram feitos em duplicatas aplicando os métodos estabelecidos no Standard Methods for the Examination of Water and Wastewater (APHA, 1995), sendo reportado resultados com as unidades, mg O2/L PtCo-APHA, FAU, e $\mathrm{mg} / \mathrm{L}$, respectivamente. Posteriormente foram verificado as condições ótimas de operação considerando diferentes dosagens de coagulante.

O coagulante tanino vegetal utilizado foi o Tanfloc SG na forma sólida fornecido pela empresa TANAC S/A, nas concentrações de: 80; 90; 100; 110; 120; 130; 140 e 150 mg/L.

\section{RESULTADOS}

Para a caracterização do efluente bruto, tomou-se os parâmetros de DQO, DBO, cor, turbidez, 
sólidos totais e dissolvidos e metais (alumínio, ferro e zinco), ao longo dos messes de março a novembro do ano de 2013, os quais foram realizado os ensaios.

A heterogeneidade do efluente bruto fica evidenciada na tabela 1, onde se observa a variação da cor, turbidez e pH ao longo do período de coleta. Verifica-se ainda que a variação do parâmetro cor é a característica mais notória no efluente, isso decorre do fato da variação na coloração do jeans empregado no processo de lavagem e da variação da quantidade de material lavado durante as coletas.

Tabela 1 - Parâmetros referentes à cor, turbidez e pH do efluente bruto no período de coleta.

\begin{tabular}{|c|c|c|c|}
\hline Coleta & Cor ( PtCo APHA) & $\begin{array}{c}\text { Turbidez } \\
\text { (FAU) }\end{array}$ & Ph \\
\hline $\mathbf{1}$ & 660 & 230 & 6,04 \\
\hline $\mathbf{2}$ & 1632 & 463 & 5,81 \\
\hline $\mathbf{3}$ & 445 & 71 & 3,30 \\
\hline $\mathbf{4}$ & 1000 & 144 & 3,62 \\
\hline $\mathbf{5}$ & 1098 & 80 & 8,31 \\
\hline $\mathbf{6}$ & 962 & 223 & 6,75 \\
\hline $\mathbf{7}$ & 638 & 147 & 6,79 \\
\hline $\mathbf{8}$ & 12320 & 4278 & 5,49 \\
\hline $\mathbf{9}$ & 1000 & 85 & 7,81 \\
\hline $\mathbf{1 0}$ & 2100 & 294 & 7,41 \\
\hline
\end{tabular}

Baseado nos parâmetros de cor, turbidez e DQO, foi determinado a concentração ótima dos coagulantes tanino e sulfato de alumínio, para o tratamento do efluente real em questão. A Figura 1 representa as porcentagens de remoção para cada concentração empregada do coagulante tanino, para os tempos TMR-5minutos, TML-30minutos e SED-30minutos. 


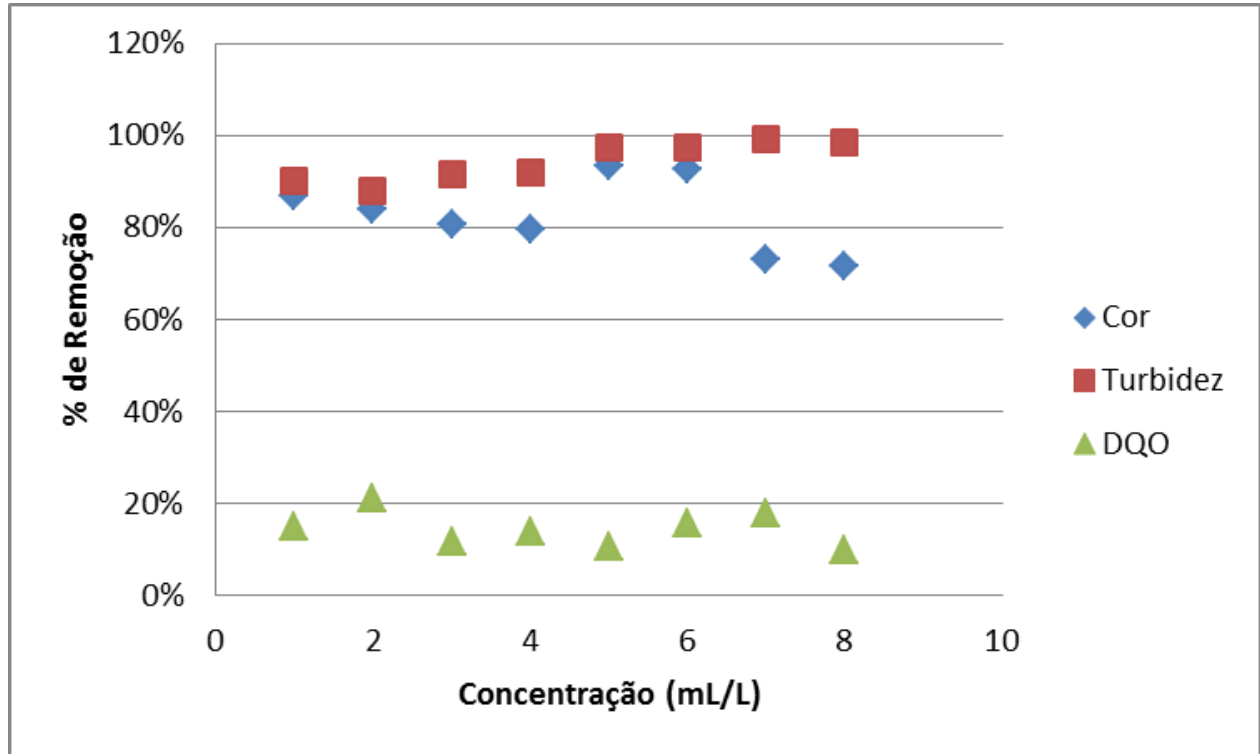

Figura 1: Porcentagens de remoção de cor, turbidez e DQO utilizando o coagulante tanino.

A Tabela 2 apresenta as porcentagens de remoção de cor, turbidez e DQO de acordo com cada ensaio. As concentrações do tanino utilizadas foram: 80; 90; 100; 110; 120; 130; 140 e 150 mg/L.

Tabela 2 - Parâmetros referentes a remoção de cor, turbidez e DQO utilizando o coagulante tanino.

\begin{tabular}{|c|c|c|c|}
\hline \multirow{2}{*}{$\begin{array}{l}\text { Dosagem } \\
(\mathrm{mg} / \mathrm{L})\end{array}$} & \multicolumn{3}{|c|}{$\%$ de Remoção } \\
\cline { 2 - 4 } & Cor & Turbidez & DQO \\
\hline 80 & $87 \%^{\mathrm{ac}}$ & $90 \%^{\mathrm{a}}$ & $15 \%^{\mathrm{a}}$ \\
\hline 90 & $84 \%^{\mathrm{abc}}$ & $88 \%^{\mathrm{a}}$ & $21 \%^{\mathrm{a}}$ \\
\hline 100 & $80 \%^{\mathrm{abc}}$ & $92 \%^{\mathrm{a}}$ & $12 \%^{\mathrm{a}}$ \\
\hline 110 & $80 \%^{\mathrm{abc}}$ & $92 \%^{\mathrm{a}}$ & $14 \%^{\mathrm{a}}$ \\
\hline 120 & $94 \%^{\mathrm{ab}}$ & $98 \%^{\mathrm{a}}$ & $11 \%^{\mathrm{a}}$ \\
\hline 130 & $93 \%^{\mathrm{a}}$ & $98 \%^{\mathrm{a}}$ & $16 \%^{\mathrm{a}}$ \\
\hline 140 & $73 \%^{\mathrm{bc}}$ & $99 \%^{\mathrm{a}}$ & $18 \%^{\mathrm{a}}$ \\
\hline 150 & $72 \%^{\mathrm{b}}$ & $98 \%^{\mathrm{a}}$ & $10 \%^{\mathrm{a}}$ \\
\hline
\end{tabular}

Na Tabela 02, após aplicar o Teste de Tukey, observa-se que ao nível de significância de 5\%, não existem diferenças significativas entre as dosagens $80 ; 90 ; 100 ; 110 ; 120 ; 130 \mathrm{mg} / \mathrm{L}$, para os três 
parâmetros estudados. Portanto, a dosagem de $80 \mathrm{mg} / \mathrm{L}$ foi considerada a melhor concentração do coagulante para o efluente tratato, e para esta concentração obtivemos remoções de $87 \%$ de cor, $90 \%$ da turbidez e $15 \%$ da matéria orgânica do efluente.

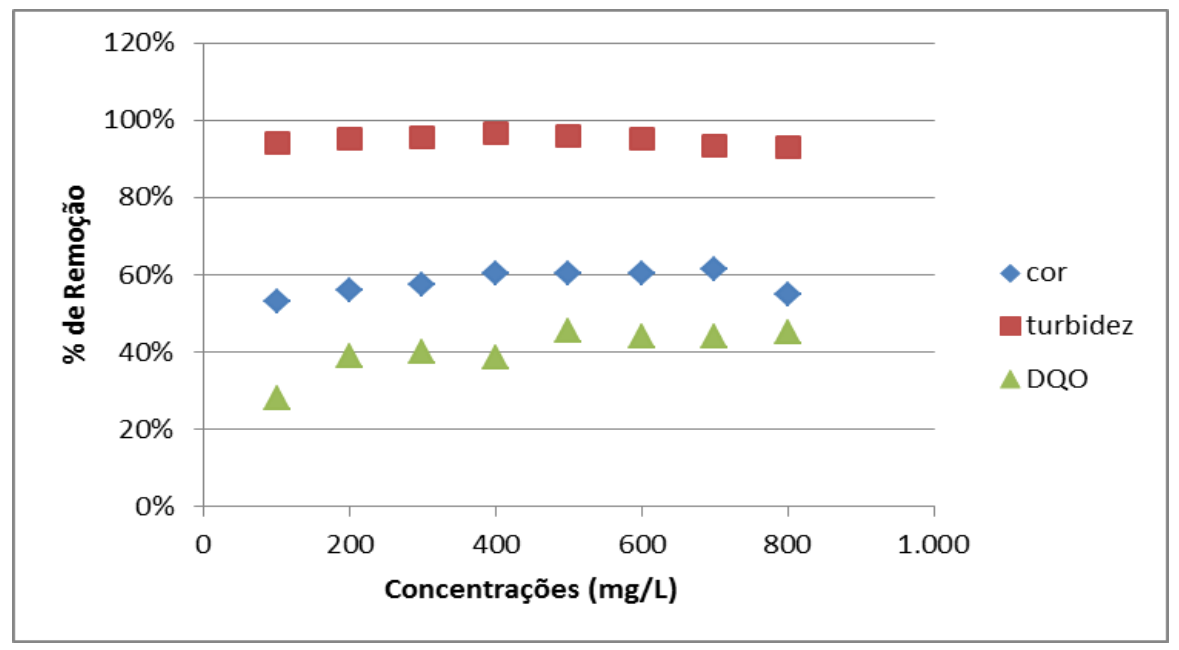

Figura 2: Porcentagens de remoção de cor, turbidez e DQO utilizando o coagulante sulfato de alumínio.

A Figura 2 representa as porcentagens de remoção para cada concentração empregada do coagulante sulfato de alumínio para os mesmos tempos: TMR-5minutos, TML-30minutos e SED30minutos.

Tabela 3 - Parâmetros referentes a remoção de cor, turbidez e DQO utilizando o coagulante sulfato de alumínio.

\begin{tabular}{|c|c|r|r|}
\hline \multirow{2}{*}{$\begin{array}{l}\text { Dosagem } \\
\text { (mg/L) }\end{array}$} & \multicolumn{3}{|c|}{ \% de Remoção } \\
\cline { 2 - 4 } & Cor & Turbidez & \multicolumn{1}{c|}{ DQ0 } \\
\hline 200 & $53 \%^{\mathrm{b}}$ & $94 \%^{\mathrm{ab}}$ & $28 \%^{\mathrm{b}}$ \\
\hline 300 & $56 \%^{\mathrm{ab}}$ & $95 \%^{\mathrm{ab}}$ & $39 \%^{\mathrm{ab}}$ \\
\hline 400 & $58 \%^{\mathrm{ab}}$ & $96 \%^{\mathrm{ab}}$ & $40 \%^{\mathrm{ab}}$ \\
\hline 500 & $61 \%^{\mathrm{a}}$ & $97 \%^{\mathrm{b}}$ & $39 \%^{\mathrm{ab}}$ \\
\hline 600 & $61 \%^{\mathrm{a}}$ & $96 \%^{\mathrm{ab}}$ & $46 \%^{\mathrm{a}}$ \\
\hline 700 & $61 \%^{\mathrm{a}}$ & $95 \%^{\mathrm{ab}}$ & $44 \%^{\mathrm{a}}$ \\
\hline 800 & $62 \%^{\mathrm{a}}$ & $94 \%^{\mathrm{ab}}$ & $44 \%^{\mathrm{a}}$ \\
\hline 900 & $55 \%^{\mathrm{ab}}$ & $93 \%^{\mathrm{a}}$ & $45 \%^{\mathrm{a}}$ \\
\hline
\end{tabular}

Como de acordo com o Teste de Tukey, os ensaios que apresentam a mesma letra sobrescrita, 
referente aos parâmetros investigados, não diferem significativamente. $\mathrm{Na}$ Tabela 3, observa-se que ao nível de significância de 5\%, não existem diferenças significativas entre as dosagens 300; 400; 500; 600; 700; 800 e 900 ml/L, para os três parâmetros estudados. Portanto, na dosagem a 300 ml/L é considerada a melhor concentração do coagulante Sulfato de Alumínio para o efluente tratado, e para esta concentração obtivemos remoções de $56 \%$ de cor, $95 \%$ da turbidez e $39 \%$ da matéria orgânica do efluente.

A comparação do estudo dos dois coagulantes no ponto ótimo, e com os mesmos tempos: TMR5minutos, TML-30minutos e SED-30minutos, podem ser observados na Figura 3.

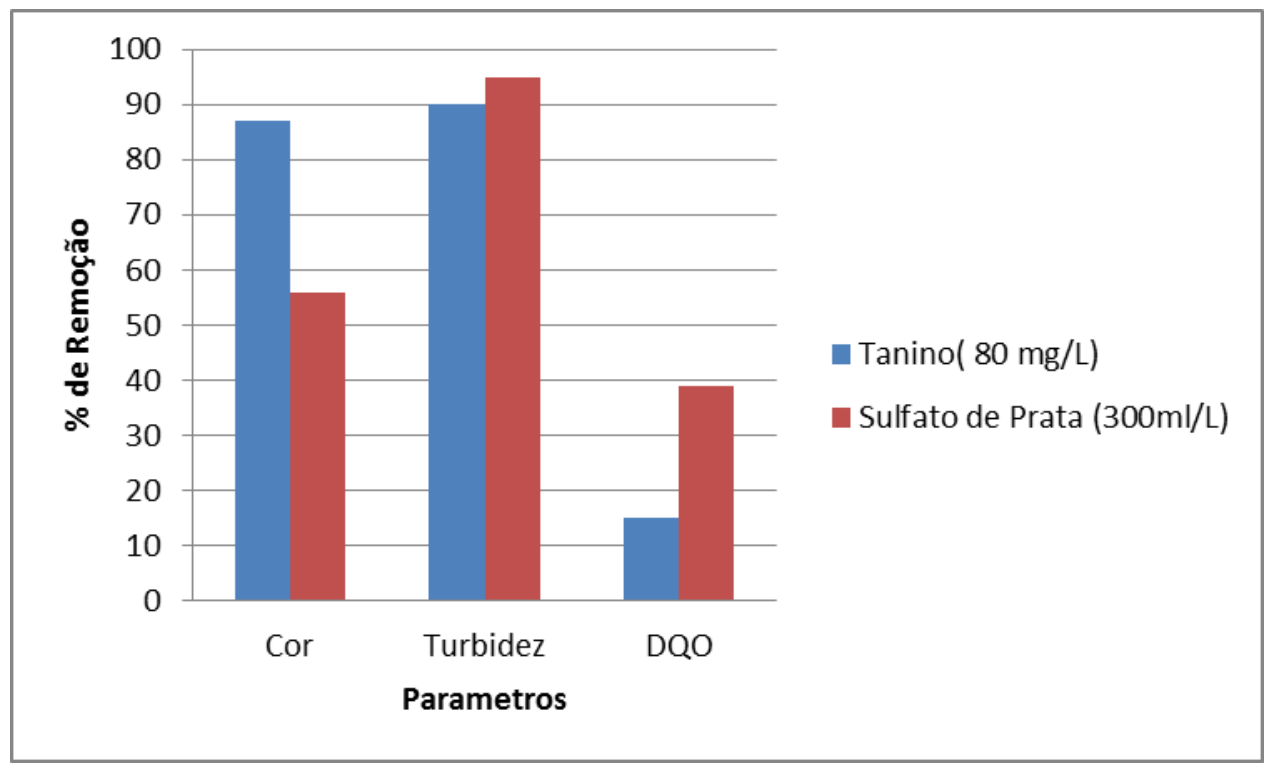

Figura 3: Comparação da redução dos parâmetros: cor, turbidez e DQO, do efluente têxtil utilizando os coagulantes tanino e sulfato de alumínio.

\section{CONCLUSÃO.}

O coagulante tanino apresentou um desempenho melhor no tratamento do efluente têxtil estudado, comparado com o coagulante sulfato de alumínio, somente no que se refere a redução do parâmetro cor, onde o tanino atinge $87 \%$ da remoção da cor em contrapartida com o coagulante sulfato de alumínio, que apresentou redução de 53\% da cor no mesmo efluente, sob mesmas condições de tratamento. Para os parâmetros turbidez e DQO, o sulfato de alumínio apresentou um desempenho melhor, sendo para a remoção de turbidez de $95 \%$ para o sulfato e $90 \%$ para o tanino, quanto a DQO o sulfato de alumínio apresentou remoção de $39 \%$ enquanto que o tanino apresentou remoção de $15 \%$. 


\section{REFERÊNCIAS}

APHA/AWWA.; Standard Methods for the examination of water and wastewater. In: CLESCERI, L.S, GREENBREG, E.; EATON, A.D. (Ed). American public health association. 20 th ed. Washington, 1995.

ARAÚJO, F.V.F.; YOKOYAMA, L.; TEIXEIRA,L. A. C. Remoção de cor em soluções de corantes reativos por oxidação com H2O2/UV. Química Nova, v. 29, p. 11 - 14, 2006.

CISNEROS, R. L.; ESPINOZA, A. G.; LITTER, M.I.; Chemosphere, 48, 393, 2002.

COUTO JUNIOR, OSÓRIO M., Tratamento de efluentes da indústria textil por coagulação e floculação utilizando polímeros naturais. (2011). Dissertação (Mestrado), Universidade do Estado de Maringá. Maringá-PR.

SAUER, T. Degradação Fotocatalítica e Corante e Efluente Têxtil. Dissertação. p.5, Florianópolis, UFSC,2002. 